\section{Liver transplantation in Greek children: 15 years experience}

\author{
loannis Xinias,' Antigoni Mavroudi,' \\ Olga Vrani, ${ }^{1}$ Georgios Imvrios, ${ }^{2}$ \\ Dimitrios Takoudas, ${ }^{2}$ \\ Kleomenis Spiroglou'
}

$13^{\text {rd }}$ Department of Pediatrics, Aristotle

University, Hippokration General

Hospital, Thessaloniki, Greece;

2Department of Surgery, Organ

Transplantation Unit, Aristotle

University, Hippokration General

Hospital, Thessaloniki, Greece

\section{Abstract}

Liver transplantation (LT) is the only available live-saving procedure for children with irreversible liver failure. This paper reports our experience from the follow-up of 16 Greek children with end-stage liver failure who underwent a LT. Over a period of 15 years, 16 pediatric liver recipients received follow up after being subjected to OLT (orthotopic liver transplantation) due to end-stage liver failure. Nine children initially presented with extrahepatic biliary atresia, 2 with acute liver failure after toxic mushroom ingestion, 2 with intrahepatic cholestasis, 2 with metabolic diseases and one with hepatoblastoma. Ten children received a liver transplant in the Organ Transplantation Unit of Aristotle University of Thessaloniki and the rest in other transplant centers. Three transplants came from a livingrelated donor and 13 from a deceased donor. Six children underwent immunosuppressive treatment with cyclosporine, mycophenolate mofetil and corticosteroids, and 7 with tacrolimus, mycophenolate mofetil and corticosteroids. Three out of 16 children died within the first month after the transplantation due to post-transplant complications. Three children presented with acute rejection and one with chronic organ rejection which was successfully managed. Five children presented with cytomegalovirus infection, 5 with Epstein-Barr virus, 2 with $\mathrm{HSV}_{1,2}, 2$ with ParvoB19 virus, 2 with varicella-zoster virus and one with $C$. Albicans infection. One child presented with upper gastrointestinal hemorrhage and one with small biliary paucity. A satisfying outcome was achieved in most cases, with good graft function, except for the patient with small biliary paucity who required retransplantation.

The long-term clinical course of liver transplanted children is good under the condition that they are attended in specialized centers.

\section{Introduction}

The first liver transplant (LT) was performed in 1963 at the University of Colorado by Starzl et al. ${ }^{1}$ in a 3 -year old child with extrahepatic biliary atresia. The patient died during the procedure due to hemorrhage. Four years later the same team performed the first successful liver transplant in an 18-month old infant with hepatoblastoma who survived for 400 days. ${ }^{2}$ In the same decade in Europe there was a high incidence of mortality after liver transplant that reached $60-70 \% 0^{3,4}$ Advances in immunosuppressive therapy and surgical techniques increased survival rates, which in some centers were over $90 \%$ the first year after transplantation in chronic liver failure and $70 \%$ in acute liver failure. Today, ten and 15-year longterm survival reaches $80 \% 0^{5.8}$ Reduced-size, split liver and living related liver transplant has markedly extended the possibility of transplantion, especially in infants under the age of one year and weighing less than $10 \mathrm{~kg} .^{9-11}$

In this country, the first LT was performed in 1992 in the Organ Transplantation Unit of Aristotle University of Thessaloniki in a 7month old boy with extrahepatic biliary atresia. He received a cadaveric transplant by using the reduced-size technique. The patient is still alive with a normal psycho-somatic development and no complications. The objective of this study is to report post-operative details of 16 pediatric patients after a liver transplant who received follow up in the Paediatric Gastroenterology Department of our hospital.

\section{Materials and Methods}

From May 1992 to June 2007, 16 pediatric liver recipients received follow up after being subjected to OLT (Orthotopic Liver Transplantation) due to end-stage liver failure. Anticoagulation was with acetylosalycylic acid at $50 \mathrm{mg}$ once daily. Six patients were started on cyclosporine $2-6 \mathrm{mg} / \mathrm{kgr} /$ day to achieve target levels of $200-400 \mathrm{ng} / \mathrm{mL}$. Seven were started on tacrolimus $0.3 \mathrm{mg} / \mathrm{kgr}$ BW/day to achieve target levels of $5-15 \mathrm{ng} / \mathrm{mL}$. All patients received immunosuppression with prednisolone which was maintained during the first post-transplant year in order to reduce the risk of side effects. Immunosuppressive therapy was given with mycophenolate mofetil at a dose of $100 \mathrm{mg} / \mathrm{m}^{2}$ SA twice daily. Table 1 represents a protocol on immunosuppression used in our Department.

ATG dosing for rejection was of $10 \mathrm{mg} / \mathrm{kg} /$ day, 4 times daily. Methylprednisolone was at a dose ranging from 100-200 mg/day IV.

All the patients have been subjected to a regular control for viral and parasitic infections
Correspondence: Ioannis Xinias, $3^{\text {rd }}$ Department of Pediatrics, Hippocration University Hospital, Konstantinoupoleos 49, GR 54642 Thessaloniki, Greece. E-mail: xinias@med.auth.gr

Key words: liver transplantation, Greek children.

Received for publication: 2 December 2009. Accepted for publication: 18 May 2010.

This work is licensed under a Creative Commons Attribution 3.0 License (by-nc 3.0).

(C) Copyright I. Xinias et al., 2010

Licensee PAGEPress, Italy

Pediatric Reports 2010; 2:e14

doi:10.4081/pr.2010.e14

due to immunosuppression (Table 2).

Demographics and the cause of liver failure in the 16 patients are reported in Table 3 . Nine patients had biliary atresia, 2 acute liver failure after toxic mushroom ingestion, one Alagille syndrome, one non-syndromic intrahepatic biliary paucity, one Wilson disease, one primary hyperoxaluria and one hepatoblastoma. Figure 1 shows the causes (\%) that led to LT in our patients. Ten children underwent LT in the Organ Transplantation Unit of Aristotle University and 6 in other medical centers.

Three out of 9 children who suffered from biliary atresia underwent a Kasai operation prior to transplantation. One of them had Kasai type I at the age of one month while the second and third underwent Kasai type II at the second and fourth month of age, respectively. The evaluation for liver insufficiency was based on the Child-Pugh criteria. According to the Child-Pugh scores, one child was classified as grade $B$ and the remaining 8 as grade $C$. In 7 cases the donor was a child, while in another 6 cases the graft was derived from an adult. In 4 out of these 6 cases the split liver technique was used. In each of these 4 cases the right lobe of the liver was allocated to an adult recipient, while the parts II and III of the grafts were allocated to children. In the other 2 cases, the parts II and III of the liver were separated by using the reduced-size technique, which means that the remaining part of the graft cannot be used.

All patients received an immunosuppressive induction with prednisolone. Maintenance immunosuppression in 13 patients consisted of mycophenolate mofetil (MMF) and a calcineurin inhibitor (cyclosporine $\mathrm{n}=6$, tacrolimus $n=7$ ). Prednisolone in every case was maintained up to one year post-transplant in order to reduce the risk of side effects. The other 3 patients died immediately after the surgical procedure. They had received a regimen of cyclosporine $(n=2)$ and tacrolimus $(n=1)$ over a few days. 


\section{Results}

Three children died within the first month due to post-transplant complications: hepatic artery thrombosis $n=1$, portal vein thrombosis $\mathrm{n}=1$, hemorrhage $\mathrm{n}=1$. The first patient was an 11-year old girl who suffered from hepatoblastoma and received graft from a cadaveric donor. The graft loss was due to hepatic artery thrombosis. The second patient was a 22 month old boy who suffered from extrahepatic biliary atresia and also received a graft from a cadaveric donor. The graft loss was due to portal vein thrombosis. The third patient was a 4year old girl with primary hyperoxaluria who died on the 30th day post-transplant due to rupture of an arterial anastomosis pseudoaneurysm. After a median period of 35 months follow up (range 23-180), 13 out of the 16 transplanted children are still alive (Figure 2).

Four children followed in our Department had at least one episode of chronic graft rejection. Two of them have been managed successfully with cortisone pulses, while anti-thymocyte globulin (ATG) was necessary in 2 other cases. In one of these cases the recipient did not have the same but an ABO-compatible blood group. The patient presented with chronic graft rejection which was managed by switching the immunosuppressive regimen from cyclosporine to tacrolimus.

Overall, a modified immunosuppressive regimen was necessary in 3 cases. Another patient who received cyclosporine presented with hypertension and increased serum and urea creatinine levels. Cyclosporine was discontinued and the patient was placed on tacrolimus. A week later the patient had normal arterial pressure as well as normal urea and creatinine levels. A patient who was on tacrolimus presented with abdominal pain and increased serum amylase which resolved after the patient was switched to cyclosporine.

Immunosuppressive complications included upper gastrointestinal hemorrhage in one patient and hyperuricemia in another. The gastrointestinal bleeding was attributed to corticosteroids as no other cause was recognized after a careful investigation which included endoscopy. The other patient who presented with hyperuricemia has been on calcineurin inhibitors for the last 14 years. Management was with a proper dietary intervention and by changing the immunosuppressive agent. The long-term follow up regarding the psychosocial development of these transplanted children revealed normal growth parameters in terms of weight gain, length and head circumference in all the children, but mild neurodevelopmental disorders in 3 of them with subnormal intellectual functioning.

Viral infections were assessed with polymerase chain reaction (PCR) and revealed

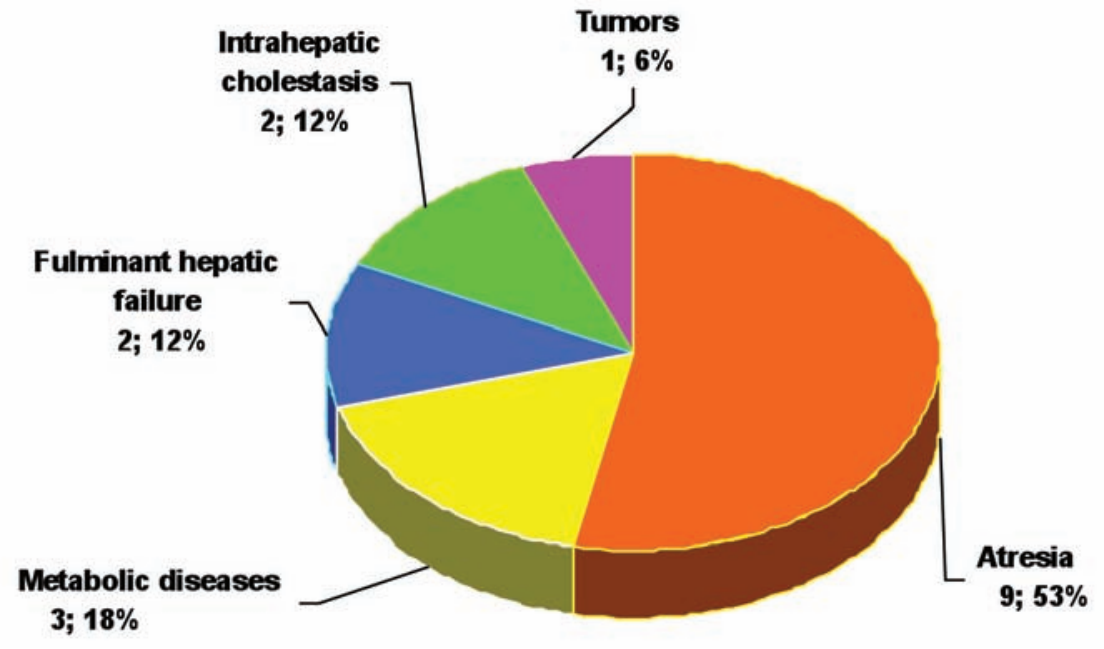

Figure 1. Causes (\%) of liver failure in our cases.

Table 1. Immunosuppressive agents used in transplanted patients.

\begin{tabular}{lll}
\hline Drug & Dose & Level \\
Cyclosporine & $\begin{array}{l}10-15 \mathrm{mg} / \mathrm{kg} \text { for } 1-2 \text { weeks, } \\
\text { then } 2-6 \mathrm{mg} / \mathrm{kg} \text { in two daily doses } \\
\text { (according to serum levels) }\end{array}$ & $200-400 \mathrm{ng} / \mathrm{mL}$ \\
Mycophenolate mofetil & $100 \mathrm{mg} / \mathrm{m}^{2}$ SA x 2 daily & \\
\hline Tacrolimus (FK 506) & $0.3 \mathrm{mg} / \mathrm{kg} /$ day twice daily, & $5-15 \mathrm{ng} / \mathrm{mL}$ \\
& $0.05 \mathrm{mg} / \mathrm{kg} /$ day IV & \\
\hline
\end{tabular}

Table 2. Follow-up schedules for infections after pediatric liver transplant.

\begin{tabular}{|c|c|c|}
\hline Exams & $\begin{array}{c}1-3 \\
\text { months }\end{array}$ & $\begin{array}{cccc}4-6 & 7-18 & 18-24 & >24 \\
\text { months } & \text { months months } & \text { months }\end{array}$ \\
\hline CMV pp65,CMV DNA & Week $1,2,3,4,5,6,8,12$,and 16 & If clinical suspicion of CMV infection \\
\hline $\begin{array}{l}\text { EBV DNA(quantitative } \\
\text { PCR on whole blood) }\end{array}$ & Week $1,2,3,4,5,6,8,12$,and 16 & Every other week \\
\hline
\end{tabular}

Serology: Hbs Ag, HbsAb,

Every 6 months

HbcAb, HbeAb, HbeAg,

HCV RNA, HAV Abs (IgG,IgM),

HSV(IgG,IgM),VZV(IgG,IgM),

Toxoplasma(IgG,IgM)

Table 3. Demographics, causes of liver failure and mean time of follow up in 16 children at the Hippokration University Hospital of Thessaloniki.

$\begin{array}{lc}\text { Age } & 4.7 \pm 2.3 \text { years } \\ \text { Mean } & 3.5 \text { years }(6 \text { months-13 years }) \\ \text { Median } & 3 \\ <1 \text { year } & 8 \\ 1-7 \text { years } & \\ 7-13 \text { years } & \\ \text { Gender } & 8 \\ \text { Male } & 8 \\ \text { Female } & \\ \text { Causes } & 9 \\ \text { Extrahepatic biliary atresia } & \\ \text { Toxic mushroom ingestion } & 2 \\ \text { Intrahepatic cholestasis } & 2 \\ \text { Metabolic diseases } & 1 \\ \text { Liver cancer } & 3.7 \text { years } \\ \text { Mean time of follow up } & \end{array}$


cytomegalovirus in 5 patients, Epstein-Barr virus in 5 patients and ParvoB19 infection in 2 patients. Two children presented with varicella-zoster viral infection, 2 with $\mathrm{HSV}^{1,2}$ and one with $C$. albicans. Infection management was with acyclovir, gancyclovir, amphotericin B and by cutting down the immunosuppression. One patient with ParvoB19 infection presented with jaundice due to small biliary paucity. $\mathrm{He}$ progressed to hepatic failure requiring retransplantation.

\section{Discussion}

The survival rate of the pediatric liver recipients followed in our department so far has been over $80 \%$ as 13 out 16 children are still alive. The recognized post-transplant complications were hepatic artery thrombosis $(n=1)$, portal vein thrombosis $(n=1)$ and rupture of an arterial anastomosis $(n=1)$. Concerning survival after transplantation, an optimum nutritional status has been shown to improve the survival rate and it was related to fewer infections and a reduction in surgical complications.

Cholestatic liver diseases lead to fat malabsorption resulting in a deficiency of calories as well as fat soluble vitamins. ${ }^{12}$ The patients have greatly benefited from caloric and vitamin supplementation, special milk formulas with medium chain triglycerides, tube feedings or parenteral feedings as indicated. Four of the patients with biliary atresia had a very low weight at presentation. Their weight increased with proper nutritional support to $20-30 \%$ before the transplantation leading to a successful outcome.

Viral infections due to immunosuppression were the second most common post-transplant complication. Patients were investigated for viral infections by means of PCR. The viruses most commonly implicated were cytomegalovirus, Epstein-Barr virus and Parvo B19 virus. Herpes Simplex virus type 1 and 2, Coxsackie virus and the mold $C$. albicans were less common causes of infection.

Children's morbidity rate after transplantation is also affected by complications due to immunosuppression. Such complications are nephrotoxicity due to calcineurin inhibitors (cyclosporine, tacrolimus), neurotoxicity, osteoporosis and cardiovascular diseases. ${ }^{13-15}$ A very important factor that has been taken into account in the choice of immunosuppressive agent is that the patient's renal function should remain intact. The newer immunosuppressive drugs, such as mycophenolate mofetil and sirolimus do not affect renal function. This means that it is possible to achieve immunosuppression by using calcineurin inhibitors at a lower dose to avoid their side effects. ${ }^{16-18}$ Only one of the patients who received cyclosporine

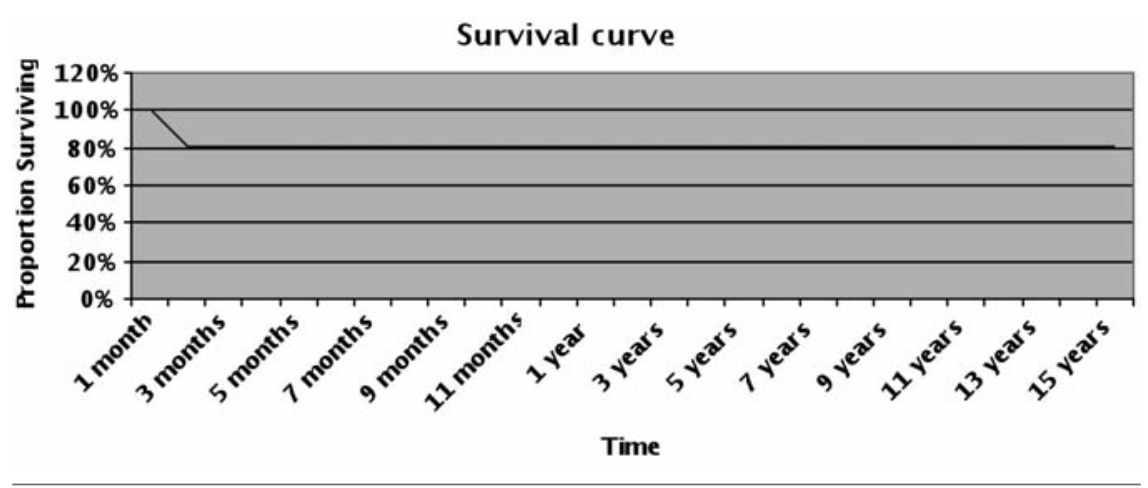

Figure 2. Survival rates of the liver transplanted patients over the last 15 years.

presented with renal insufficiency, increased urea levels and arterial hypertension. The patient was initially managed by reducing the dose of cyclosporine and concomitantly by placing the patient on tacrolimus.

Mental and cognitive disorders are common in children after liver transplant. These may be attributed to hepatic encephalopathy as a result of fulminant or chronic liver failure prior to transplantation. Prolonged hospitalization and immunosuppressive regimens used after transplantation, particularly corticosteroids, have also been implicated for mental disorders. Cognitive disorders were present in 2 of the children who were transplanted due to fulminant liver failure after mushroom ingestion. Minor learning disabilities were also present in the child who was transplanted for Alagille syndrome and was mainly attributed to prolonged hospitalization. Assessment was with the WISC III intelligence test (Weschler Intelligence Scale For Children) which illustrated a mild mental retardation.The growth parameters, such as the weight and length percentiles and the head circumference percentile in relation to age and sex were within the normal range in all the patients according to Greek growth scales.

The number of candidates requiring a liver transplant continuously increases as the indications for performing transplantation have expanded. Allocating the available liver grafts to the candidates has always been a major issue. Patient evaluation to determine the priority for transplantation is currently based on the stage of the liver insufficiency according to the ChildTurcotte-Pugh score and also by taking into account the co-existing complications of the primary liver disease, such as ascites, hepatocellular carcinoma and variceal bleeding. 9,20

Compared to adults, pediatric patients who have undergone LT are less likely to experience a relapse of the primary liver disease. This observation has been confirmed by the higher survival proportion of the grafts in the pediatric patients compared to adults.

ABO type seems to be a significant factor in rejection. It is generally agreed that the balance between the expression of $\mathrm{ABO}$ blood group antigens and the recipient's natural antibodies has a marked effect on liver graft survival rates. A comparison of liver graft survival rates in $\mathrm{ABO}$-identical and $\mathrm{ABO}$-compatible but not identical cases showed the ABOidentical survival rates were superior to those in the ABO-compatible/non-identical group. ${ }^{21}$

In conclusion, today LT is a treatment of choice for children with end-stage liver failure due to irreversible liver damage caused by a vast majority of pediatric diseases which could not be managed in the past. Cooperation among a team of experts (hepatologists, transplant surgeons, psychiatrists, nurses, social workers) with the patient's family is of outstanding importance for a successful management of the liver disease. Future approaches such as the use of allo-grafts or hepatocytes, or even blastocytes, may reduce the number of children who currently require liver grafts from compatible donors.

\section{References}

1. Starzl TE, Marchioro TL, Vonkaulla KN, et al. Homotransplantation of the liver in humans. Surg Gynecol Obstet 1963;117: 659-76.

2. Starzl TE. History of Liver and Other Splanchnic Organ Transplantation. In: Busutill RW, Klintmalm GB, eds. Transplantation of the Liver. Philadelphia, Pa: W.B. Saunders 1996:3-22.

3. Otte JB. History of pediatric liver transplantation. Where are we coming from? Where do we stand? Pediatr Transplant 2002;6:378-87.

4. Alagille D. History of pediatric liver transplantation in Europe. Acta Gastroenterol Belg 2004;67:172-5.

5. Schafer DF. Liver transplantation. Looking back, looking forward. In: Maddrey WC, Schiff ER, Sorrell MF, eds. Transplantation of the Liver. Philadelphia, Pa: Lippincott, Williams, \& Wilkins; 2001.

6. Kelly DA. Current results and evolving indications for liver transplantation in 
children. J Pediatr Gastroenterol Nutr 1998;27:214-21.

7. Busuttil RW, Farmer DG, Yersiz H, et al. Analysis of long-term outcomes of 3200 liver transplantations over two decades: a single-center experience. Ann Surg 2005; 241:905-16.

8. Lee WS, McKiernan P, Kelly DA. Etiology, outcome and prognostic indicator of childhood fulminant hepatic failure in the United Kingdom. J Pediatr Gastroenterol Nutr 2005;40:575-81.

9. de Ville de Goyet J, Hausleithner V, Reding $\mathrm{R}$, et al. Impact of innovative techniques on the waiting list and results in pediatric liver transplantation. Transplantation 1993;56:1130-6.

10. Inomata $\mathrm{Y}$, Tanaka J, Okajima $\mathrm{H}$, et al. Living related liver transplantation for children younger than one year old. Eur J Pediatr Surg 1996;6:148-51.

11. Kelly DA. Liver Transplantation. In: Walker WA et al., eds. Pediatric Gastrointestinal
Disease. Philadelphia, Pa: BC Decker; 2000:1272-90.

12. McDiarmid SV. Management of the pediatric liver transplant patient. Liver Transpl 2001;7: S77-86.

13. Chang FY, Singh N, Gayowski T, et al. Fever in liver transplant recipients: changing spectrum of etiologic agents. Clin Infect Dis 1998; 26:59-65.

14. Reding R. Tacrolimus in pediatric liver transplantation. Pediatr Transplant 2002; 6:447-51

15. Nobili V, Comparcola D, Sartorelli MR, et al. Mycophenolate mofetil in pediatric liver transplant patients with renal dysfunction: preliminary data. Pediatr Transplant 2003; 7:454-7.

16. Evans HM, McKiernan P, Kelly DA. Mycophenolate mofetil for renal dysfunction after pediatric liver transplantation. Transplantation 2005;79:1575-80.

17. Tumgor G, Arikan C, Kilic M, et al. Frequency of hyperuricemia and effect of calcineurin inhibitors on serum uric acid levels in liver transplanted children. Pediatr Transpl 2006;10:665-8.

18. Bucuvalas JC, Ryckman FC. Long-term outcome after liver transplantation in children. Pediatr Transplant 2002;6:30-6.

19. Graziadei I. Liver transplantation organ allocation between Child and MELD. Wien Med Wochenschr 2006;156:410-5.

20. Brown RS Jr, Kumar KS, Russo MW, et al. Model for end-stage liver disease and Child-Turcotte-Pugh score as predictors of pretransplantation disease severity, posttransplantation outcome, and resource utilization in United Network for Organ Sharing status 2A patients. Liver Transpl 2002;8:278-84.

21. Ohashi Y, Iwaki Y, Yagihashi A. Effect of blood group matching on liver transplant survival rates. J Hep Pancr Surg 1995;2: 134-8. 